\title{
Cassava: its polymer, fiber, composite, and application
}

\begin{abstract}
Cassava is a type of plant which has different purposes of use. It is used to produce various foods, bio-fibres, bio-composites and bio-polymers. Besides, it is now used as renewable energy source of starch. The intention of the paper is to focus on the importance of cassava fibres, polymers and composites as well as its potential applications, another focus point of this research is the biodegradable polymer development which is taken out from cassava starch. Moreover, this work gives a comprehensive review about surface treatments as well as the most recent developments of cassava polymer/fibre based bio-composites and the summary of main result presented in the literature, focusing on properties of cassava composite and applications. These applications were related to various industrial application as well as others such as the production of xylenes, ethanol and bio-fuel, food, food packaging and cassava foam.
\end{abstract}

